\title{
PENERAPAN SISTEM AKUNTANSI PENGGAJIAN DALAM KAITANNYA DENGAN SISTEM MANAJEMEN MUTU (ISO 9001:2008) \\ (STUDI KASUS PADA PT. RAHAYU SANTOSA)
}

\author{
Saras Ayu Adistya Nurdini dan Iriyadi
}

\author{
JI. Raya Jakarta Bagor KM. 47, Kelurahan Nanggewer Mekar RT. 03 RW \\ 02, Kecamatan Cibinong, Bogor \\ Aras.adistya@yahoo.co.id
}

\section{Abstract}

The accounting system is a very complex system in a company, it is necessary to ensure the system processes the company is running consistently and efficiently to produce a good performance. One way that can be applied to achieve the goal or objective is to be a synergy with the accounting system of quality management systems (ISO 9001: 2008) which is usually referred to by the International Standard Organization (ISO). Quality management system standards (ISO 9001: 2008) is a system that has standards or quality is good, which is already international. Quality management system standards (ISO 9001: 2008) is an international standard that is no stranger to manufacturing and service industries. Standards become mandatory for many manufacturers or companies to be able to compete in the international market, by demonstrating the consistency of the product quality. The purpose of this paper is: the first is knowing the payroll accounting system implementation at PT. Rahayu Santosa, second is knowing the implementation of quality management system (ISO 9001: 2008) at PT. Rahayu Santosa, and last is knowing payroll accounting system implementation in relation to the quality management system (ISO 9001: 2008) at PT. Rahayu Santosa. The methodology used in this study is the descriptive research method that studies carried out by means of a variable to describe and explain research on the author, as well as action research methods to obtain the necessary data.

Payroll accounting system at PT. Rahayu Santosa still use the manual payroll accounting system or not computerized. Payroll accounting systems applied by PT. Rahayu Santosa is in conformity with the existing SOP PT. Rahayu Santosa and not found during the major findings of internal audit. Payroll system part of the ISO 9001 on the HR department.

ISO 9001: 2008 is a quality management system standards issued by international organizations, which means that the product is not certified, but how to set up the system. The quality management system (ISO 9001: 2008) is a system implemented by PT. Rahayu Santosa in order to improve the quality of a product (goods or services). PT. Rahayu Santosa is one of the manufacturing companies that implement ISO 9001: 2008 since 2008. 
Application of payroll accounting system does not have a direct relation with the quality management system (ISO 9001: 2008), but the quality management system (ISO 9001: 2008) ensure the procedure is good payroll system.

Keywords : ISO 9001:2008 and Accounting System

\section{Pendahuluan}

Dengan berkembangnya perusahaan yang diakibatkan dari pesatnya perkembangan perekonomian nasional maupun global, maka akan meningkat pula aktivitas yang harus dilakukan untuk mencapai tujuan perusahaan yaitu memperoleh laba atas hasil usaha yang dijalankan. Untuk memperoleh laba yang optimal, perusahaan harus dapat menggunakan sumber daya yang penting yang harus dimiliki oleh perusahaan, diantaranya: modal, metode yang digunakan, mesin, ataupun sumber daya manusia yang dimiliki perusahaan. Sumber daya manusia atau karyawan yang dimiliki perusahaan merupakan salah satu faktor penting dalam kegiatan perusahaan, karena karyawan memberikan sumbangan tenaga, pikiran, dan keahliannya dalam operasi perusahaan. Kompensasi yang diterima karyawan dari perusahaan adalah gaji yang merupakan imbalan balas jasa dalam bentuk uang yang diterima oleh karyawan (tenaga kerja) berdasarkan kesepakatan yang telah ditentukan sebelumnya. Sehingga bagi perusahaan gaji merupakan biaya yang cukup besar jumlahnya dan salah satu unsur yang memiliki banyak resiko kemungkinan terjadinya manipulasi dan pemborosan.

Prosedur penggajian yang baik seharusnya dijalankan dengan efektif. Untuk itu maka diperlukan sistem akuntansi penggajian yang baik, untuk menunjang informasi yang relevan sebagai sarana komunikasi yang dapat digunakan untuk pengambilan keputusan. Sistem akuntansi merupakan serangkaian dari formulir-formulir, catatan-catatan, laporan-laporan, serta alatalat lainnya yang dikoordinasikan sehingga memberikan informasi yang diperlukan pimpinan perusahaan dalam pengambilan keputusan. Karena sistem akuntansi merupakan sistem yang sangat kompleks dalam suatu perusahaan, maka diperlukan sistem yang menjamin proses-proses yang ada diperusahaan berjalan secara konsisten dan efisien sehingga menghasilkan kinerja perusahaan yang baik.

Dengan kata lain, dalam setiap perusahaan perlu menerapkan sistem akuntansi keuangan, agar perusahaan dapat memiliki acuan atau panduan dalam menjalankan bisnis perusahaannya. Menurut AIMS Consultan, salah satu cara yang dapat diterapkan untuk mencapai sasaran atau tujuan tersebut adalah harus adanya sinergi antara sistem akuntansi dengan sistem manajemen mutu (ISO 9001:2008) yang biasanya disebut dengan International Standard Organization (ISO). Standar sistem manajemen mutu (ISO 9001:2008) merupakan sistem yang memiliki standar atau kualitas yang sudah baik, yang sudah international. Standar sistem manajemen mutu (ISO 9001:2008) merupakan standar internasional yang sudah tidak asing lagi untuk industri manufaktur dan jasa. Standar menjadi wajib bagi banyak produsen atau perusahaan untuk dapat bersaing di pasar internasional, dengan menunjukkan konsistensi mutu produk yang dihasilkan.

Penerapan standar sistem manajemen mutu (ISO 9001:2008) dapat digunakan sebagai bukti bahwa produsen atau perusahaan telah berusaha menghasilkan produk atau jasa dengan mutu/kualitas yang baik dan juga dengan kinerja yang akan semakin meningkat. 
Berdasarkan latar belakang tersebut, maka penulis tertarik untuk melakukan penelitian yang berjudul "PENERAPAN SISTEM AKUNTANSI PENGGAJIAN DALAM KAITANNYA DENGAN SISTEM MANAJEMEN MUTU (ISO 9001:2008) (STUDI KASUS PT. RAHAYU SANTOSA)“.

Adapun identifikasi masalah yang mendasari dalam penelitian ini, yaitu sebagai berikut :

1. Bagaimana penerapan sistem akuntansi penggajian pada PT. Rahayu Santosa?

2. Bagaimana penerapan sistem manajemen mutu (ISO 9001:2008) pada PT, Rahayu Santosa?

3. Bagaimana penerapan sistem akuntansi penggajian dalam kaitannya dengan sistem manajemen mutu (ISO 90001:2008) pada PT. Rahayu Santosa?

\section{Objek dan Metodologi Penelitian}

Mempertimbangkan sifat dari hubungan antar variabelnya, maka penelitian ini disusun berdasarkan dua variabel dependen dan satu variabel independen, sebagai berikut :

\begin{tabular}{|c|c|c|}
\hline Variabel / Sub variable & Indikator & Skala / Ukuran \\
\hline $\begin{array}{ll}- & \text { Sistem Akuntansi } \\
\text { Penggajian } \\
\text { (Independen / X) }\end{array}$ & $\begin{array}{ll}\text { - } & \text { Prosedur Kepegawaian } \\
\text { - } & \text { Prosedur Pencatat Waktu } \\
\text { - } & \text { Prosedur Pembuat Daftar } \\
& \text { Gaji } \\
\text { - } & \text { Prosedur Pembayaran Gaji } \\
\text { - } & \text { Fungsi Kepegawaian } \\
\text { - } & \text { Fungsi Pencatat Waktu } \\
\text { - } & \text { Fungsi Pembuat Daftar Gaji } \\
\text { - } & \text { Fungsi Akuntansi } \\
\text { - } & \text { Fungsi Keuangan } \\
\text { - } & \text { Dokumen yang digunakan }\end{array}$ & $\begin{array}{l}\text { - Ordinal } \\
\text { - } \text { Ordinal } \\
\text { - } \text { Ordinal } \\
\text { - Ordinal } \\
\text { - Ordinal } \\
\text { - Ordinal } \\
\text { - Ordinal } \\
\text { - Ordinal } \\
\text { - Ordinal } \\
\text { Ordinal }\end{array}$ \\
\hline $\begin{array}{ll}\text { - } & \text { Sistem Manajemen } \\
\text { Mutu (ISO } \\
\text { 9001:2008) } \\
\text { (Dependen / Y) }\end{array}$ & $\begin{array}{ll}\text { - } & \text { Sasaran Mutu } \\
\text { - } & \text { Analisis Data } \\
\text { - } & \text { Audit Internal } \\
\text { - } & \text { Pengendalian } \\
& \text { Mutu }\end{array}$ & $\begin{array}{l}\text { - Ordinal } \\
\text { - Ordinal } \\
\text { - Ordinal } \\
\text { - Ordinal }\end{array}$ \\
\hline
\end{tabular}

Berdasarkan data yang diperoleh dari penelitian, masih diperlukan pengolahan lebih lanjut. Hal ini dimaksudkan untuk memperoleh seluruh gambaran yang lebih jelas guna memecahkan masalah-masalah yang sedang diteliti, dengan demikian akan mempermudah untuk menarik kesimpulan mengenai permasalahan yang dihadapi. Metode analisis yang digunakan dalam penelitian ini adalah analisis deskriptif yaitu mengumpulkan data secara teoritis untuk menilai suatu implementasi yang nyata sebagai praktek yang sesungguhnya.

Data yang dikumpulkan guna penelitian ini merupakan data primer dan sekunder. Untuk data primer tersebut bersumber dari lembaga dimana riset 
dilakukan dan hasil hasil konfirmasi (wawancara) dengan pihak terkait selama penelitian. Sedangkan data sekunder diperoleh dengan cara penelusuran kepustakaan dan literatur dari beberapa referensi buku maupun homepage (situs website). Berdasarkan cara memperoleh data, metode yang telah dilakukan, yaitu : metode observasi, tinjauan pustaka dan wawancara.

\section{Hasil dan Pembahasan}

Dasar gaji pokok yang diterima setiap karyawan PT. Rahayu Santosa adalah berdasarkan standart gaji pokok (UMK) yang biasanya dikeluarkan oleh Surat keputusan gubernur kab. Bogor setiap tahun. Selain itu, PT. Rahayu Santosa memiliki kebijakan atas gaji pokok yang diterima karyawannya, yaitu berdasarkan lama bekerja, pendidikan terakhir, disertai dengan tunjangantunjangan yang dipengaruhi oleh jabatan karyawan. Selain tunjangan, adapun potongan-potongan yang dibebankan perusahaan kepada karyawannya, yaitu antara lain potongan pajak penghasilan (PPh 21) dan premi asuransi yang ditanggung oleh pegawai.

\subsection{Sistem Akuntansi Penggajian pada PT. Rahayu Santosa}

Untuk memenuhi perhitungan dan pembayaran gaji karyawan yang sesuai, maka dalam menerapkan sistem akuntansi penggajian, PT. Rahayu Santosa telah memiliki beberapa unsur-unsur akuntansi penggajian, antara lain:

\section{a. Fungsi yang terkait,}

Fungsi-fungsi yang terkait dalam sistem akuntansi penggajian pada PT. Rahayu Santosa adalah :

\section{1) Fungsi Kepegawaian}

PT. Rahayu Santosa, fungsi kepegawaian ditangani oleh lbu Telly, yang memiliki tanggung jawab untuk mencari dan menyeleksi karyawan baru (recruitment) yang dibutuhkan oleh PT. Rahayu Santosa. Kemudian bertanggung jawab dalam memutuskan penempatan karyawan baru, mutasi karyawan, dan pemberhentian karyawan.

\section{2) Fungsi Pencatat Waktu}

Fungsi pencatat waktu di PT. Rahayu Santosa ditangani oleh lbu Titis, yang bertanggung jawab membuat rekapan data absensi karyawan perusahaan. Rekap data absensi karyawan ini berfungsi sebagai acuan fungsi pembuat daftar gaji dalam menghitung total gaji yang akan diterima setiap karyawan. Fungsi pencatat waktu ini terpisah dengan fungsi operasi atau fungsi pembuat daftar gaji, sesuai dengan yang disyaratkan dalam sistem pengawasan.

\section{3) Fungsi Pembuat Daftar Gaji}

Fungsi pembuat daftar gaji di PT. Rahayu Santosa ditangani oleh Ibu Sri Purwaningsih, yang bertanggung jawab untuk membuat daftar gaji karyawan. Daftar gaji tersebut berisi penghasilan bruto yang menjadi hak karyawan, serta berbagai potongan yang menjadi beban setiap karyawan selama jangka waktu pembayaran gaji. 


\section{4) Fungsi Akuntansi}

Fungsi akuntansi pada PT. Rahayu Santosa ditangani oleh Ibu Adhiyanti, yang bertanggung jawab untuk mencatat kewajiban yang timbul dalam hubungannya dengan pembayaran gaji karyawan.

\section{5) Fungsi Keuangan}

Fungsi keuangan pada PT. Rahayu Santosa ditangani Oleh Ibu Rohana yang bertanggung jawab untuk mengisi check guna pembayaran gaji. Pembayaran gaji pada perusahaan ini dilakukan melalui Bank BCA.

\section{b. Dokumen Yang Digunakan}

Dokumen yang digunakan dalam sistem akuntansi penggajian pada PT. Rahayu Santosa, adalah sebagai berikut :

\section{1) Kartu Jam Hadir}

PT. Rahayu Santosa menggunakan dokumen ini hanya untuk karyawan tertentu, seperti Security. Kartu jam hadir ini diisi dengan mesin pencatat waktu. Sedangkan untuk karyawan seperti operator/staff, kabag, manager, dan direktur, perusahaan telah dapat melihat jam hadir karyawan tersebut dari program yang terlink dengan mesin handkey. Kartu jam hadir ini berfungsi untuk mencatat waktu hadir karyawan.

\section{2) Daftar Gaji}

Di PT. Rahayu Santosa dokumen ini berisi jumlah total gaji bruto setiap karyawan, dikurangi potongan-potongan berupa PPh Pasal 21, utang karyawan, iuran untuk organisasi karyawan, potongan absensi, dan potongan lainnya. Daftar gaji ini berfungsi sebagai acuan fungsi keuangan membayar gaji setiap karyawan).

\section{3) Rekap Daftar Gaji}

Di PT. Rahayu Santosa dokumen ini merupakan ringkasan gaji per departemen, yang dibuat berdasarkan daftar gaji. Rekap daftar gaji ini berfungsi sebagai acuan bagian pembuat daftar gaji dalam membuat PPU, serta dokumen yang digunakan bagian accounting dalam mencatat biaya gaji yang dikeluarkan.

\section{4) Bukti Kas Keluar}

Pada PT. Rahayu Santosa, bukti kas keluar merupakan dokumen perintah pengeluaran uang yang disebut dengan PPU (permohonan pengeluaran uang). Bukti kas keluar ini dibuat oleh bagian HRD, yaitu oleh fungsi pembuat daftar gaji yang kemudian akan diberikan kepada bagian accounting dan bagian keuangan. PPU ini dibuat berdasarkan informasi dari rekap daftar gaji secara total seluruh biaya gaji. PPU ini berfungsi sebagai dasar permohonan pengeluaran uang oleh bagian HRD ke bagian keuangan.

\section{5) Voucher Slip Gaji}

Voucher slip gaji merupakan dokumen yang berisi perincian gaji karyawan berupa gaji pokok, tunjangan jabatan, tunjangan lain-lain, rapelan, insentif, uang lembur, uang makan dan transport yang dikurangi dengan potongan-potongan berupa potongan absensi, 
potongan uang makan dan transport, NISP, SPSI (iuran untuk organisasi karyawan), JHT, JKN, Koperasi (luran untuk organisasi karyawan), potongan lain-lain, serta PPh Pasal 21. Dokumen ini diberikan kepada setiap karyawan PT. Rahayu Santosa per akhir bulan pada saat gaji dibayarkan. Voucher slip gaji ini berfungsi untuk memberikan informasi total gaji yang diterima setiap karyawan.

\section{6) Bukti Setor Bank}

Bukti setor ini diisi oleh bagian keuangan, berdasarkan PPU (permohonan pengeluaran uang) dan disetorkan ke bank. Bukti setor ini berfungsi sebagai acuan pihak bank dalam melakukan pembayaran.

\section{c. Prosedur yang Membentuk Sistem Akuntansi Penggajian}

Prosedur-prosedur yang membentuk sistem akuntansi penggajian pada PT. Rahayu Santosa, adalah sebagai berikut :

\section{1) Bagian Kepegawaian}

Pada prosedur ini, fungsi kepegawaian pada PT. Rahayu Santosa menyiapkan surat penempatan karyawan baru, surat mutasi dan rotasi karyawan, dan surat pemberhentian karyawan, selama sebulan. Kemudian lembar pertama dokumen surat keputusan perubahan data karyawan tersebut didistribusikan kepada fungsi pembuat daftar gaji, sebagai acuan untuk membuat nilai gaji yang akan diterima karyawan. Dan lembar kedua dokumen surat keputusan perubahan data karyawan diarsip berdasarkan tanggal.

\section{2) Bagian Pencatat Waktu}

Pada prosedur ini, fungsi pencatat waktu pada PT. Rahayu Santosa menyiapkan data absensi karyawan. Kemudian data tersebut diberikan kepada fungsi pembuat daftar gaji, sebagai acuan untuk membuat nilai gaji yang akan diterima karyawan secara soft copy.

\section{3) Bagian Pembuat Daftar Gaji}

Pada prosedur ini, fungsi pembuat daftar gaji menerima data absensi karyawan dan surat keputusan perubahan data karyawan. Kemudian fungsi pembuat daftar gaji membuat laporan gaji karyawan dan rekapitulasi gaji karyawan berdasarkan dokumen dan data yang diterima. Serta membuat permohonan pengeluaran uang dengan nilai total yang sesuai pada rekapitulasi gaji karyawan dan membuat voucher slip gaji. Kemudian lembar pertama dokumen rekapitulasi gaji karyawan dan permohonan pengeluaran uang (PPU) rangkap 3 (tiga) didistribusikan kepada fungsi akuntansi untuk di verifikasi. Sedangkan lembar pertama laporan detail gaji karyawan diberikan kepada fungsi keuangan, sebagai acuan dalam membayarkan gaji kepada masing-masing karyawan. Lembar kedua laporan detail dan rekapitulasi gaji karyawan diarsipkan berdasarkan tanggal. Setelah semua pembayaran gaji dilakukan, bagian pembuat daftar gaji akan membagikan voucher slip gaji ke setiap departemen, yang nantinya oleh setiap departement dibagikan ke setiap karyawan di departemen tersebut. 
4) Bagian Akuntansi

Pada prosedur ini, fungsi akuntansi menerima rekapitulasi gaji karyawan dan dokumen permohonan pengeluaran uang (PPU) rangkap 3 (tiga) yang kemudian diverifikasi. Jika sesuai, maka dokumen PPU tersebut ditandatangani oleh manager accounting. Kemudian bagian staff accounting mencatat kewajiban yang timbul atas pembayaran gaji karyawan, contohnya utang gaji dan utang pajak. Atas pencatatan kewajiban tersebut akan menghasilkan voucher jurnal. Lembar pertama dokumen PPU akan didistribusikan ke bagian keuangan, lembar kedua dokumen PPU dan voucher jurnal akan diarsip berdasarkan tanggal, dan lembar ketiga dokumen PPU akan diberikan kembali ke bagian HRD.

\section{5) Bagian Keuangan}

Dalam prosedur ini, bagian akuntansi bertugas dalam proses pembayaran gaji. Bagian keuangan menerima laporan detail gaji karyawan dan dokumen PPU yang akan menjadi dasar bagian keuangan dalam membuat giro. Giro akan ditanda tangan oleh manager finance. Setelah itu, bagian keuangan akan mendatangi Bank yang bekerja sama dengan perusahaan, yaitu Bank BCA. Untuk melakukan pembayaran gaji karyawan melalui kliring. Namun, jika dana yang ada pada bank tersebut tidak mencukupi, maka bagian keuangan akan melakukan setor tunai.

\section{d. Catatan Akuntansi Yang Digunakan}

Catatan akuntansi yang digunakan di PT. Rahayu Santosa adalah sebagai berikut :

\section{1) Jurnal umum}

Pada PT. Rahayu Santosa jurnal umum dicatat oleh fungsi keuangan, bagian jurnal. Dalam sistem akuntansi penggajian di PT. Rahayu Santosa, jurnal umum digunakan untuk mencatat distribusi biaya tenaga kerja ke setiap departemen perusahaan. Serta mencatat setiap kewajiban yang timbul dalam hubungannya dengan gaji pembayaran gaji karyawan (voucher jurnal umum dapat dilihat pada lampiran 6). Contoh jurnal yang terbentuk pada saat mencatat pembayaran gaji dan mengakui hutang gaji, adalah :

\#Jurnal pembayaran gaji (tax)

$\begin{array}{ll}\text { By. Gaji Adm. } & X X X \\ \text { By. Gaji Adm. Produksi } & \text { XXX } \\ \text { Kas Kantor } & \end{array}$

$\mathrm{XXX}$

\#Jurnal pembayaran gaji (non tax)

$\begin{array}{ll}\text { By. Gaji Adm } & X X X \\ \text { By. Tunjangan Makan } & X X X \\ \text { By. Tunjangan Transportasi } & X X X \\ \text { By. Lembur } & X X X \\ \text { By. Kesejahteraan Lainnya } & X X X\end{array}$

Kas Kantor 
\# Jurnal pembayaran gaji (non tax)

By. Gaji Adm

$X X X$

By. Tunjangan Makan

$X X X$

By. Tunjangan Transportasi $\quad$ XXX

By. Lembur

$X X X$

Kas Pabrik

$X X X$

\# Jurnal atas hutang gaji

By. Gaji Adm

$X X X$

By. Gaji Produksi

$X X X$ Hutang Gaji

$X X X$

\subsection{Sistem Manajemen Mutu Penggajian (ISO 9001:2008)}

PT. Rahayu Santosa telah tercatat dalam sistem manajemen mutu (ISO 9001:2008) dan mendapat sertifikat ISO 9001:2008 sejak tahun 2008. ISO 9001:2008 pada PT. Rahayu Santosa telah mencakup seluruh departemen yang ada di perusahaan. Dengan kata lain, semua prosedur yang ada disetiap departemen telah masuk ISO 9001:2008, termasuk dengan sistem penggajian pada departemen HRD. ISO 9001:2008 ini diterapkan dalam PT. Rahayu Santosa, agar prosedur-prosedur yang dijalankan dapat konsisten.

\section{a. Sasaran Mutu}

Pada ISO 9001:2008, salah satu manfaat penerapannya adalah untuk meningkatkan motivasi, moral, dan kinerja karyawan serta sistem yang terdokumentasi. Dengan meningkatkan motivasi, moral, dan kinerja karyawan, maka dapat pula meningkatkan kepuasaan pelanggan serta secara tidak langsung dapat mempengaruhi peningkatan laba perusahaan. Pada PT. Rahayu Santosa, sasaran mutu ISO 9001:2008 di departemen HRD adalah keterlambatan karyawan, absensi, rotasi dan mutasi, tingkat kecelakaan kerja dan alur dokumen yaitu dari keakurasian data sampai dengan proses pembayaran pada sistem penggajian.

Semua sasaran mutu di departemen HRD tersebut memiliki target persentase berbeda-beda. Misalnya, keterlambatan karyawan dan absensi memiliki target persentase sebesar $5 \%$. Kemudian target untuk rotasi/mutasi adalah minimal 1 orang setiap bulannya, dan $0 \%$ untuk target persentase terhadap kecelakaan kerja. Serta 100\% untuk target persentase terhadap alur dokumen mulai dari keakurasian data sampai dengan proses pembayaran. Dalam proses mencapai sasaran mutu pada sistem penggajian, PT. Rahayu Santosa membuat tabel gaji pokok karyawan tetap maupun karyawan kontrak sebagai data pendukung. PT.Rahayu Santosa membuat tabel gaji berdasarkan dengan surat keputusan gubernur Kab. Bogor setiap tahun, sebagai acuan dasar kenaikan gaji pokok. Adapun perbedaan besaran gaji yang diterima adalah gaji pokok ditambah dengan kebijakan PT. Rahayu Santosa, yaitu berdasarkan lama bekerja, pendidikan terakhir, disertai tunjangantunjangan yang dipengaruhi oleh jabatan karyawan.

Pada PT. Rahayu Santosa, cara mengukur sasaran mutu adalah dengan membandingkan rencana dan aktual yang dilihat pada laporan monitoring sasaran mutu. Contohnya adalah rencana target pada absensi karyawan adalah 1000 menit setiap bulan atau sama dengan $5 \%$, namun aktualnya adalah 4000 menit pada bulan Juli 2014 atau sama dengan $20 \%$. Contoh lain adalah rencana target pada alur 
dokumen di sistem penggajian adalah 100\%, dengan semua keakurasian data (termasuk data pendukung) sampai dengan proses pembayaran dan aktual yang ada pada PT. Rahayu Santosa di bulan maret 2014 adalah 100\%. Sehingga dari laporan monitoring sasaran mutu tersebutlah dapat diambil informasi pencapaian target atas sasaran mutu tersebut.

\section{b. Audit Internal}

Audit Internal pada PT. Rahayu Santosa dilakukan oleh internal auditor yang independen, sesuai dengan persyaratan sistem manajemen mutu (ISO 9001:2008) yaitu pada klausal 8.2.2 Audit Internal. Namun internal auditor pada PT. Rahayu Santosa belum memiliki sertifikat training audit internal, hanya memiliki pengalaman dan mengikuti training audit internal yang diselenggarakan oleh departement QMR (Quality Management Representative) selama seminggu dengan jadwal yang ditentukan oleh departemen QMR (biasanya dibulan oktober minggu kedua). Pada klausal 8.2.2 ini juga tidak didapati pernyataan secara tegas, bahwa auditor harus memiliki sertifikat training audit internal.

Persyaratan tentang kompetensi secara umum diatur dalam klausal 6.2.1 tentang persyaratan umum sumber daya manusia. Pada Klausul 6.2.1 disebutkan bahwa personel yang melaksanakan pekerjaan yang mempengaruhi kesesuaian terhadap produk harus memiliki kompetensi atas dasar pendidikan, pelatihan, keterampilan, dan pengalaman yang sesuai. Berdasarkan klausal 6.2.1 tersebutlah, departemen QMR melakukan pemilihan auditor. Dalam pemilihan auditor, departemen QMR memiliki beberapa kandidat yang didapat berdasarkan kesukarelaan dan perwakilan tiap-tiap departemen di PT. Rahayu Santosa. Kemudian kandidat-kandidat auditor tersebut mengikuti training selama seminggu dan mengikuti test secara tertulis.

Hasil test tersebut menjadi dasar kriteria auditor yang kompeten di PT. Rahayu Santosa. Hasil test tersebut memiliki poin standar yang ditetapkan bagian ISO (departemen QMR) setiap tahunnya. Poin standar atas hasil test tersebut adalah poin 80 pada tahun 2014. Jika dalam hasil test tersebut tidak ada kandidat yang memenuhi kriteria poin, maka akan dilakukan test ulang sebanyak $3 x$. Jika sampai dilakukan test $3 x$ dan belum ada kandidat yang lolos. Maka departemen QMR akan mencari kandidat baru.

Sehingga dengan kata lain, walaupun personil internal auditor PT. Rahayu Santosa belum memiliki sertifikat training audit internal, namun personil internal auditor sudah cukup kompeten dalam menjadi internal auditor di PT. Rahayu Santosa. Audit internal yang dilakukan di PT. Rahayu Santosa sesuai dengan tujuan audit internal dalam sistem manajemen mutu, yaitu memperhatikan bukti ketidaksesuaian pada sistem manajemen mutu, menilai kebutuhan untuk tindakan perbaikan dan peningkatan, dan memelihara kesiapan akan mutu, serta untuk memastikan bahwa prosedur yang dijalankan konsisten dan telah sesuai dengan sistem manajemen mutu.

Jika adanya temuan dalam melakukan audit internal, maka auditor akan melaporkan temuan tersebut secara tertulis dalam formulir checklist audit mutu internal dan daftar temuan audit mutu internal. 


\section{c. Pengendalian Rekaman Mutu}

Dalam penerapan sistem manajemen mutu (ISO 9001:2008), pengendalian rekaman mutu merupakan suatu bukti kesesuaian terhadap persyaratan dan penerapan yang efektif dari sistem manajemen mutu. Pengendalian rekaman mutu yang dilakukan di PT. Rahayu Santosa, dimulai dari mengidentifikasi form, kemudian merapihkan/menyusun rekaman sesuai karakteristik, serta menetapkan cara pengendalian catatan, misalnya dengan memberi nomor pada masing-masing form, agar dapat teridentifikasi dengan mudah ketika dibutuhkan. Kemudian mengirimkan daftar induk form dan penyimpanan dokumen ke DC (Document Controller) ISO, serta pemeliiharaan seluruh dokumen termasuk rekaman dan memantau masa simpan minimal 1 tahun atau sesuai dengan kebijakan masing-masing departemen. Jika telah melewati masa simpan, maka harus diidentifikasi apakah akan ada perubahan masa simpan atau akan dimusnahkan.

Pengendalian rekaman mutu ini bertujuan agar bukti atas dokumen-dokumen yang berkaitan di masing-masing departemen dapat disimpan, dipelihara, dan teridentifikasi dengan baik. Sehingga ketika bukti dokumen tersebut dibutuhkan dengan cepat dan mudah, dapat diambil kapan saja. Seperti contoh di departemen HRD, pengendalian rekaman mutu dilakukan pada dokumen data absensi karyawan, rekap gaji karyawan, laporan detail gaji karyawan, dan voucher jurnal yang terbentuk.

Jika terdapat dokumen yang sudah melewati masa simpannya, dan akan dimusnahkan, maka fungsi yang terkait tersebut harus mengisi form pemusnahan dokumen atas dokumen yang akan dimusnahkan. Form pemusnahan dokumen dibuat untuk mengurangi volume dokumen yang lama atau sudah kadaluarsa.

\section{d. Analisis Data}

Dalam sistem manajemen mutu, analisis data diperlukan untuk memperlihatkan kesesuaian dan efektivitas sistem manajemen mutu, dan menggunakannya untuk perbaikan berkesinambungan dan masuk dalam klausal 8.4 Analisis Data. Analisis data yang dilakukan oleh departemen HRD yang berkaitan dengan sistem penggajian mencakup analisis data pada alur dokumen (prosedur), diantaranya analisis data pada fungsi yang terkait, analisis data pada dokumen yang digunakan, dan analisis data pada catatan akuntansi yang digunakan. Analisis data ini berfungsi untuk memperlihatkan kesesuaian data dan efektivitas sistem akuntansi penggajian yang ada pada PT. Rahayu Santosa. Di PT. Rahayu Santosa pada departemen HRD, analisis data ini dilakukan oleh Manager HRD.

\subsection{Penerapan Sistem Akuntansi Penggajian Dalam Kaitannya Dengan Sistem Manajemen Mutu (ISO 9001:2008)}

Penerapan sistem akuntansi penggajian pada PT. Rahayu Santosa masih menggunakan sistem akuntansi penggajian secara manual atau belum terkomputerisasi. Secara pengendalian intern, penerapan sistem akuntansi penggajian pada PT. Rahayu Santosa sudah baik.

Sistem manajemen mutu (ISO 9001:2008) adalah sistem yang diterapkan oleh PT. Rahayu Santosa guna meningkatkan kualitas suatu produk (barang atau jasa). Karena, selain berguna dalam meningkatkan kualitas suatu barang, penerapan ISO 9001:2008 ini juga bermanfaat untuk meningkatkan 
motivasi, moral, dan kinerja karyawan. Dengan meningkatnya motivasi, moral, dan kinerja karyawan, maka secara tidak langsung akan mempengaruhi laba perusahaan ataupun kualitas barang yang dihasilkan.

Selain itu, dalam sistem manajemen mutu (ISO 9001:2008) terdapat beberapa klausal yang berkaitan dengan sumber daya manusia. Yang artinya, bagian yang terkait dalam perusahaan, contohnya departemen HRD harus menjalankan klausal-klausal tersebut sesuai dengan ISO 9001:2008. Pada PT. Rahayu Santosa, departemen HRD sudah menjalankan klausal-klausal dalam ISO 9001:2008 yang berkaitan dengan sumber daya manusianya, seperti sasaran mutu, audit internal, pengendalian rekaman mutu, dan analisis data, walaupun terkadang masih ditemukan ketidaksesuaian antara prosedur ISO 9001:2008 dengan aktualnya.

Ditemukannya ketidaksesuaian itu adalah hasil dari audit internal yang dilakukan oleh PT. Rahayu Santosa. Contoh temuan ketidaksesuaian antara prosedur dengan aktualnya adalah dokumen rekap data absensi karyawan diberikan secara soft copy oleh fungsi pembuat pencatat waktu kepada fungsi pembuat daftar gaji, yang seharusnya diberikan juga secara hard copy.sehingga temuan dalam audit internal adalah pengendalian dokumen, yang bersifat obervasi, yang artinya masih ada dokumen yang tidak teridentifikasi.

Berdasarkan pernyataan diatas, dapat disimpulkan bahwa penerapan sistem akuntansi penggajian tidak berkaitan secara langsung dengan sistem manajemen mutu (ISO 9001:2008). Namun dengan menerapkan sistem manajemen mutu (ISO 9001:2008) dapat menjamin bahwa prosedur sistem akuntansi penggajian sudah baik serta menjamin prosedur-prosedur lain yang ada di perusahaan secara konsisten.

\section{Simpulan}

Berdasarkan uraian diatas, maka dapat diambil beberapa simpulan. Diantaranya yaitu :

1. Penerapan sistem akuntansi penggajian pada PT. Rahayu Santosa masih dilakukan secara manual. Namun sistem akuntansi penggajian yang diterapkan sudah sesuai dengan SOP yang ada di PT. Rahayu Santosa dan tidak ditemukan temuan yang mayor pada saat audit internal. Dan Sistem akuntansi penggajian bagian dari ISO 9001 pada departemen HRD.

2. ISO $9001: 2008$ adalah suatu standar sistem manajemen mutu yang dikeluarkan oleh organisasi internasional, yang artinya bukan produk yang disertifikasi melainkan bagaimana mengatur sistemnya. PT. Rahayu Santosa adalah salah satu perusahan manufaktur yang menerapkan sistem ISO 9001:2008 sejak tahun 2008. Dan penerapan ISO 9001:2008 dikontrol oleh bagian Quality Management Representative (QMR).

3. Penerapan sistem akuntansi penggajian tidak memiliki kaitan secara langsung dengan sistem manajemen mutu (ISO 9001:2008), namun sistem manajemen mutu (ISO 9001:2008) menjamin prosedur sistem penggajian sudah baik. 


\section{Daftar Pustaka}

Agoes, Soekrisno. 2004. Auditing (Pemeriksaan Akuntan). Edisi Tiga. Jakarta : Lembaga Penerbit Fakultas Ekonomi Ul.

Anisa, Fudy. Analisis Sistem Informasi Akuntansi Penggajian Pada PT. Pertani (Persero). Universitas Gunadarma. Depok.

Dunia, Firdaus A. 2013. Pengantar Akuntansi. Edisi Keempat. Jakarta : Lembaga Penerbit Fakultas Ekonomi UI.

Gaspersz, Vincent. 2002. Total Quality Management. Jakarta : Gramedia Pustaka Utama.

Hall, James A. 2007. Accounting Information System. Edisi Empat. Jakarta : Salemba Empat.

Hall, James A. 2009. Sistem Inforvbmasi Akuntansi. Edisi Empat Buku Satu. Jakarta : Salemba Empat. Penerjemah Dewi Fitriasari S.S.,M.Si. dan Deny Arnos Kwary S.S., M.Hum.

Hery, SE, Msi. 2014. Pengantar Akuntansi 2. Jakarta : Lembaga Penerbit Fakultas Ekonomi UI.

Kurniadi, Dedy. 2012. Penerapan Sistem Manajemen Mutu ISO 9001 dan API Speq Q1 di PT. Pipa Mas Putih Sebagai Bagian Business Rules Perusahaan. STMIK Putera, Batam.

Mardi. 2011. Sistem Informasi Akuntansi. Bogor : Ghalia Indonesia.

Maulana, Arief. 2011. Analisis Penerapan Sistem Manajemen Mutu ISO 9001:2008 Pada Kantor Manajemen Mutu Institut Pertanian Bogor. Institut Pertanian Bogor. Bogor.

Modul Pelatihan ISO 9001:2008. 2009. Internal Quality Audit. Jakarta : AIMS Consultants.

Mubarak, M.M. and Syarif, R., 2006. Dampak Pelatihan Kerja Terhadap Kualitas Kerja Karyawan. Jurnal IImiah Kesatuan Nomor, 8(20), p.2.

Mulyadi. 2008. Sistem Akuntansi. Edisi Tiga. Jakarta : Salemba Empat.

Nugroho, Aditya. 2007. ISO 9001 Leading You The Way. Jakarta : PT. AIMS Perdana.

Pengertian dan Dimensi Mutu. 2012. Available at: http://pendidikanekonomi.com. (diakses tanggal 20 November 2013)

Pengertian ISO 9001:2008. Available at: http://m.forum.detik.com. (diakses tanggal 24 Agustus 2013)

Primatika, Aditya. 2009. Analisis Efektifitas Sistem Informasi Akuntansi Penggajian Karyawan (Studi Kasus di Perusahaan Daerah Air Minum Kabupaten Malang). Universitas Brawijaya. Malang.

Putra, Lie Dharma. 2011. Artikel Accounting, Finance, and Taxation. Available at: Accounting-Financial-Tax.com (diakses tanggal 25 Agustus 2014)

Purnama, Nursya'ban. 2006. Manajemen Kualitas Perspektif Global. Cetakan Pertama. Ekonisia. Yogyakarta.

Resmi, Siti. 2011. Perpajakan Teori dan Kasus. Edisi Enam Buku Satu. Jakarta : Salemba Empat.

Reeve, Warren, Duchac, Wahyuni, dkk. 2009. Pengantar Akuntansi Adaptasi Indonesia. Buku Satu. Jakarta : Salemba Empat. Penerjemah : Damayanti Dian.

Sadeli, Lili M. 2006. Dasar-dasar Akuntansi. Edisi satu Cetakan ketiga. Jakarta : PT. Bumi Aksara.

Simamora, Henry. 2004. Manajemen Sumber Daya Manusia. Edisi Ketiga. Yogyakarta : STIE YKPN.

Soemarso S.R . 2009. Akuntansi Suatu Pengantar 1. Edisi Empat. Jakarta : Rineka Cipta. 
Widjaja, Amin. 2010. Dasar-dasar Akuntansi Keuangan Ikhtisar Teori dan Tanya Jawab. Jakarta : Penerbit Harvarindo. 
